\title{
Long-Term Effect of a Short Sucrose/Xylitol Exposure on Survival of Permanent Teeth: A Practice-Based Study
}

\author{
Päkkilä $\mathrm{J}^{1}$, Hangasmaa $\mathrm{H}^{2}$, Halunen $\mathrm{I}^{2}$, Laitala $\mathrm{M}-\mathrm{L}^{2}$, Anttonen $\mathrm{V}^{2,3, *}$ \\ ${ }^{1}$ Department of Mathematical Sciences, University of Oulu, Finland \\ ${ }^{2}$ Department of Cariology, Endodontology, and Pediatric Dentistry, Research Unit of Oral Health Sciences, University of Oulu, Finland \\ ${ }^{3}$ Medical Research Center, University of Oulu and Oulu University Hospital, Finland
}

${ }^{*}$ Corresponding author: Anttonen V, Department of Cariology, Endodontology, and Pediatric Dentistry, Research Unit of Oral Health Sciences, University of Oulu, Finland; Email: vuokko.anttonen@oulu.fi

Received: April 12, 2019; Accepted: April 18, 2019; Published: May 01, 2019;

\section{SUMMARY}

Background: In the original trial preschool children were randomly divided into two groups: 8,4g xylitol or sucrose chewing gum for two months, to investigate xylitol's effect on acute titis media (AOM). Salivary mutans streptococci $\left(\mathrm{sm}\right.$ ) levels were taken before and after trial. Sm levels $\geq 10^{5} \mathrm{CFU} / 1 \mathrm{ml}$ were considered high and those $<10^{5} \mathrm{CFU} / 1 \mathrm{ml}$ low. Eighteen months after the exposure, oral health of the participants was investigated from patient records of the City of Oulu, Finland. If not available, the individuals were invited for check-up. Two months sucrose exposure caused a significant caries risk in primary dentition in high sm group.

Aim: Aim of this study was to examine the effect of sucrose/xylitol intervention of preschool children on their caries experience in following 10 years. Design Oral health data of the participants in AOM-trial were collected for analyses covering the period 2003-2008/2009 from the City of Oulu, Finland patient records with their permission. Kaplan-Meyer survival curves were drawn for each tooth. Statistical significance of difference in survival between groups was analysed by Wilcoxon test.

Results: There was no statistifically significant difference between xylitol and sucrose groups in the survival of any permanent teeth caries free. Low sm levels seemed to be a protective factor against caries. Caries history in pre-school age was the best predictor of caries experience in teenage.

Conclusions: Short sucrose exposure at preschool age does not increase the risk for permanent tooth decaying. Two months regular exposure to xylitol is too short for preventing caries in long run.

\section{INTRODUCTION}

The evidence of the role of sucrose in the manifestation and progression of dental caries is inevitable [1,2]. Widely used as a substitute for sucrose, xylitol has been reported to reduce caries incidence and have even anticariogenic potential [3]. Caries reduction based on xylitol's ability to decrease the number of mutans streptococci in saliva and to inhibit plaque formation [4]. is reported to be at greatest during the first year of the eruption of teeth [5]. Additionally to numerous caries prevention research, the impact of xylitol on prevention of acute otitis media (AOM) has been investigated [6,7].

The present study is based on a randomized clinical trial conducted in 1995 [8], which investigated the impact of two-month regular use of xylitol chewing gum on prevention of AOM among children in a Finnish municipal day care center. Children in the intervention group got xylitol chewing gum whereas the control group got sucrosesweetened chewing gum. Additionally, the growth inhibiting effect of xylitol against Streptococcus pneumoniae in pharynx of the children was examined. As an outcome, the two-month frequent xylitol exposure had a preventive effect against AOM but the carriage rate of $S$. pneumoniae between the xylitol and sucrose groups was not discovered. The use of sucrose chewing gum among the control group raised a question about the ethics of the study [9]. The rationale for the permission given by Finnish ethics committee for this AOM study was that the participants had regular dental check-ups in the Finnish municipal dental health care system [10]. Teeth of the children were not investigated prior or after the study, but salivary mutans streptococci levels before and after the trial were recorded [11]. All children were also customers of the municipal oral health care of the City of Oulu. At that time all children were examined at regular basis.

Findings of a study on the short-term effects of the original AOM trial did not indicate an increased risk of dental caries in the sucrose group of the original study population per se [11]. However, two months' regular sucrose exposure for preschool aged children with high mutans streptococci levels at baseline caused a significant caries risk in primary dentition [11]. Analyses were carried out about two years after the original AOM trial.

The aim of the present study was to examine if a two-month daily sucrose/xylitol exposure had effects on caries prevalence 10 years later considering mutans streptococci levels at baseline. The hypothesis was that short sucrose/xylitol exposure at preschool age does not indicate permanent tooth decay 10 years later regardless of salivary mutans streptococci levels at baseline. 


\section{MATERIAL AND METHODS}

\section{Subjects}

Original double-blinded, randomized, clinical intervention trial (AOM trial) was conducted in April-May 1995 in the city of Oulu, Finland [8]. Altogether 306 children in 11 day care centers were recruited and were randomly divided to those getting either sucrose or xylitol chewing gum for two months. The intervention group $(\mathrm{n}=157$, mean age $5.0 \pm 1.4$ ) received $8.4 \mathrm{~g}$ xylitol a day (two pieces of chewing gum five times a day). Similar amount and number of pieces of sucrose gum were distributed for the sucrose group ( $n=149$, mean age $4.9 \pm 1.5$ ). Children in both groups attended municipal dental health care according to the normal schedule and individual need, including dental examinations, and necessary non-invasive and invasive treatments. No extra examinations nor preventive dental care were planned for the participants the trial. For the short-term analyses [11], data on oral health of 286 children was available for collection in the patient files of the municipal health care centre of the city of Oulu. Those with no data in the records after 1995, were clinically examined 18 months after the baseline trial [11].The xylitol group comprised 70 girls and 76 boys and, when the respective numbers in sucrose group were 76 and 64 (Table 1).

Table 1. Frequencies and distributions according to gender, intervention group and mutans streptococci $(\mathrm{ms})$ level at baseline, ms level values of 19 children are missing.

\begin{tabular}{|l|c|c|c|}
\hline \multirow{2}{*}{ Group } & \multicolumn{2}{|c|}{ Gender n (\%) } & \\
\cline { 2 - 4 } & Boy & Girl & Total \\
\hline Sucrose & $64(45.7)$ & $76(54.3)$ & 140 \\
\hline Xylitol & $76(52.1)$ & $70(47.9)$ & 146 \\
\hline & $140(49.0)$ & $146(51.0)$ & 286 \\
\hline ms + & $42(58.3)$ & $30(41.7)$ & 72 \\
\hline ms - & $89(45.6)$ & $106(54.4)$ & 195 \\
\hline & $131(49.1)$ & $136(50.9)$ & $267 *$ \\
\hline
\end{tabular}

*19 missing

\section{Data}

In 2008-2009, oral health data during the period 2003-2008 of participants in AOM trial, were collected from the electronic patient files for analyses of the present study (Figure 1). A gap of 6 years (1997-2003) was caused by the fact that electronic system was not yet in use in Oulu. From patient files number of dental visits and examinations, caries lesions and restorations in permanent teeth were recorded by one author (IH). Observations on caries lesion were considered dentine caries or deeper, demanding restorative or endodontic treatment or extraction.

Salivary mutans streptocci samples of the participants were taken before (baseline, $n=257)$ and after the AOM trial in $1995(n=245)$ from the oral mucosa with a swab by an oral hygienists of the municipal health center of the city of Oulu. The samples were cultivated following the manufacturer's protocol (Dentocult $\mathrm{SM}^{\circledR}$, Orion Diagnostica:
Espoo, Finland). The participants were divided into two groups according to their mutans streptococci levels at baseline: $\geq 10^{5}$ mutans streptococci CFU in one $\mathrm{ml}$ saliva was considered high level (ms+), and $<10^{5}$ low level $\left(\mathrm{ms}^{-}\right)^{2}$.

\begin{tabular}{|c|c|}
\hline \multicolumn{2}{|c|}{ AOM trial $1995^{\circ}$} \\
366 children recruited, 30 dropped out \\
\hline $\mathrm{n}=157$ children & $\mathrm{n}=149$ children \\
$\begin{array}{c}\text { xylitol 8.4g daily } \\
\text { (chewing gum) for 2 months }\end{array}$ & $\begin{array}{c}\text { sucrose } 8.4 \mathrm{~g} \text { daily } \\
\text { (chewing gum) for 2 months }\end{array}$ \\
\hline \multicolumn{2}{|c|}{ Salivary mutans streptococci tests } \\
at baseline $(\mathrm{n}=257)$ and after intervention $(\mathrm{n}=245)$
\end{tabular}

Short-term dental health $1997^{11}$
$\mathrm{n}=286$
Oral health data collected from the patient files of Municipal
Health Centre of city of Oulu
Data of 20 children not available

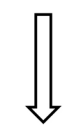

Long-term dental health (present study)
$\mathrm{n}=239$
Oral health data $2003-2008$ collected from the patient files of
Municipal Health Centre of city of Oulu
Data of 47 children not available

Figure 1. Flow chart of the study protocol.

\section{Statistical analyses}

Frequencies and distributions according to gender, intervention group and ms level at baseline and after the intervention were calculated using cross-tabulation. Statistical significance was studied by chi-squared test. Mean DMF values according to age and original mutans streptococci levels (ms+/ms-) were calculated for the years 2005-2008 when the participants were 13-20 years old. The number/ proportion of participants with healthy dentitions $(\mathrm{dmf}+\mathrm{DMF}=0)$ were determined in 1997 and 2007. For studying the change in mutans streptococci levels after sucrose/xylitol intervention cross-tabulation and a 2-sample test for equality of proportions were used.

The time from the birth of the child to the onset of dental caries lesion needing a restoration was recorded during the follow-up period separately for each permanent tooth. Non-parametric Kaplan-Meyer survival curves were drawn for each tooth to examine the survival of all permanent teeth caries free during the follow-up period. In the analysis, right censoring was used if there was no caries leading to restoration placed during the follow-up period. Wilcoxon test was used to investigate the statistical significance of difference of survival 
Päkkilä J, Hangasmaa H, Halunen I, Laitala M-L and Anttonen V (2019) Long-Term Effect of a Short Sucrose/Xylitol Exposure on Survival of Permanent Teeth: A Practice-Based Study

in sucrose and xylitol groups and also dividing the participants into sub groups according to their ms levels. To avoid pseudo replication, each tooth on one side of both jaws (maxilla and mandible) was chosen for the statistical analyses; for the pictures, however, data from both contralateral teeth were combined.

The association of caries status at baseline with the caries status 13 years after the intervention was analysed using a linear regression model; $\mathrm{dmf}+\mathrm{DMF}$ at baseline as independent variable and DMF 13 years after intervention representing the outcome measure. An equation of the association was achieved.

The data were analyzed using SPSS (version 20.0, SPSS, Inc., Chicago, Il, USA), and R (version 2.11.1 Patched): a language and environment for statistical computing ( $\mathrm{R}$ Foundation for Statistical Computing, Vienna, Austria, URL http://www.R-project.org), and SAS (version 9.2, SAS Institute Inc., Cary, NC, USA) software. Statistically significant difference between the groups was determined with p-values $<0.05$.

\section{Ethics}

Ethical Committee of the City of Oulu had approved the original AOM trial and approval for this study was not necessary. Approval for collecting data from the dental records was received from the Chief of the Municipal Health Services of the City of Oulu. All participants were included in the study if their parents gave approval for it. Data in analyses did not include any personal identifications.

\section{RESULTS}

In 2008-2009, more than 10 years after the original sucrose/xylitol intervention trial, patient records of 239 participants were available for analyses, drop-out rate from the original $\mathrm{AOM}$ study ${ }^{8}$ being $22 \%$ and from the short-term dental health study in 1997 [11] 16\%, respectively (Figure 1). On average 5.2 dental examinations per individual were performed during the entire follow-up period; 5.0 dental examinations in the sucrose group and 5.4 in the xylitol group (n.s.). Combinig both groups, the mean interval between dental examinations was 442 days before 1997 and 722 days during the period 2003-2008.

Mean DMF values between 2005 and 2008 varied between 0.259.25, with higher variation in ms+ than ms- group (Table 2). In 1997 the proportion of those with $\mathrm{dmf} / \mathrm{DMF}=0$ in the $\mathrm{sm}+$ group was lower than in the sm- group ( $51 \%$ vs. $77 \%$ ). Ten years later the proportions were lower but the difference remained (17\% vs. $35 \%)$ n.s. (Table 3 ).

Mutans streptococci levels were recorded at baseline and after the trial for 122 children in sucrose group and 123 children in xylitol group. Levels remained either unchanged or changed only slightly among majority of the children during the trial despite the intervention group. In the xylitol group, ms levels decreased more and increased less than in the sucrose group, but the differences between the groups were not statistically significant (Table 4).

No significant difference between the intervention group was found in survival of any permanent tooth caries free. As an example, Kaplan-Meier curves of maxillary incisors and first and second permanent molars were drawn (Figures 2 and 3). There was a tendency that the first molars became decayed sooner in the sucrose than in the xylitol group but not for them nor for any other molars the differences between the groups were statistically significant (Figure 3). During the 10-year-follow-up period, survival time of permanent teeth of individuals with high ms levels and having been in sucrose group was not significantly different from those in other subgroups. However, participants with high ms levels at baseline tended to have more caries lesions in the first molars than those with low ms levels. This was seen more undoubtedly in the first than in the second molars (Figure 4).

Table 2. Mean DMF during the years 2005-2008 according to the age and mutans streptococci (ms) levels.

\begin{tabular}{|c|c|c|c|c|c|}
\hline \multicolumn{6}{|c|}{ Mean DMF } \\
\hline \multirow[b]{2}{*}{ Year } & \multirow[b]{2}{*}{ Age } & \multicolumn{2}{|c|}{ ms - } & \multicolumn{2}{|c|}{ ms + } \\
\hline & & $\mathbf{n}$ & DMF & $\mathbf{n}$ & DMF \\
\hline \multirow[t]{3}{*}{2005} & 13 & 9 & 2.89 & 4 & 0.25 \\
\hline & 16 & 10 & 1.80 & 5 & 3.00 \\
\hline & 17 & 11 & 4.09 & 4 & 9.25 \\
\hline \multirow[t]{3}{*}{2006} & 14 & 8 & 2.88 & 1 & 1.00 \\
\hline & 17 & 11 & 3.91 & 1 & 1.00 \\
\hline & 18 & 11 & 3.55 & 5 & 7.80 \\
\hline \multirow[t]{3}{*}{2007} & 15 & 5 & 2.40 & 3 & 1.00 \\
\hline & 18 & 4 & 2.25 & 4 & 3.00 \\
\hline & 19 & 1 & 2.00 & 4 & 5.75 \\
\hline \multirow[t]{3}{*}{2008} & 16 & 8 & 5.75 & 2 & 1.00 \\
\hline & 19 & 2 & 4.00 & 0 & \\
\hline & 20 & 2 & 1.50 & 0 & \\
\hline Total & & 92 & & 33 & \\
\hline
\end{tabular}

Table 3. Number of healthy dentitions $(\mathrm{dmf} / \mathrm{DMF}=0)$ after two months' sucrose/xylitol intervention (1997) and ten years later (2007) according to age and mutans streptococci (ms) levels.

\begin{tabular}{|c|c|c|c|c|c|c|c|c|c|}
\hline \multicolumn{10}{|c|}{$\mathbf{d m f} / \mathrm{DMF}=0$} \\
\hline \multicolumn{5}{|c|}{ Year 1997} & \multicolumn{5}{|c|}{ Year 2007} \\
\hline & \multicolumn{2}{|c|}{ sm - } & \multicolumn{2}{|c|}{ sm +} & & \multicolumn{2}{|c|}{ sm - } & \multicolumn{2}{|c|}{ sm +} \\
\hline Age & $\mathbf{n}$ & $\%$ & $\mathbf{N}$ & $\%$ & Age & n & $\%$ & $\mathbf{n}$ & $\%$ \\
\hline 4 & 6 & 67 & 1 & 100 & 14 & 1 & 0 & 0 & \\
\hline 5 & 21 & 86 & 7 & 43 & 15 & 5 & 20 & 3 & 67 \\
\hline 6 & 26 & 85 & 8 & 38 & 16 & 11 & 36 & 2 & 0 \\
\hline 7 & 37 & 78 & 15 & 53 & 17 & 4 & 25 & 4 & 0 \\
\hline 8 & 19 & 79 & 8 & 38 & 18 & 4 & 25 & 4 & 0 \\
\hline 9 & 21 & 62 & 9 & 0 & 19 & 1 & 0 & 4 & 0 \\
\hline 10 & 0 & & 1 & 9 & & & & & \\
\hline
\end{tabular}


Päkkilä J, Hangasmaa H, Halunen I, Laitala M-L and Anttonen V (2019) Long-Term Effect of a Short Sucrose/Xylitol Exposure on Survival of Permanent Teeth: A Practice-Based Study

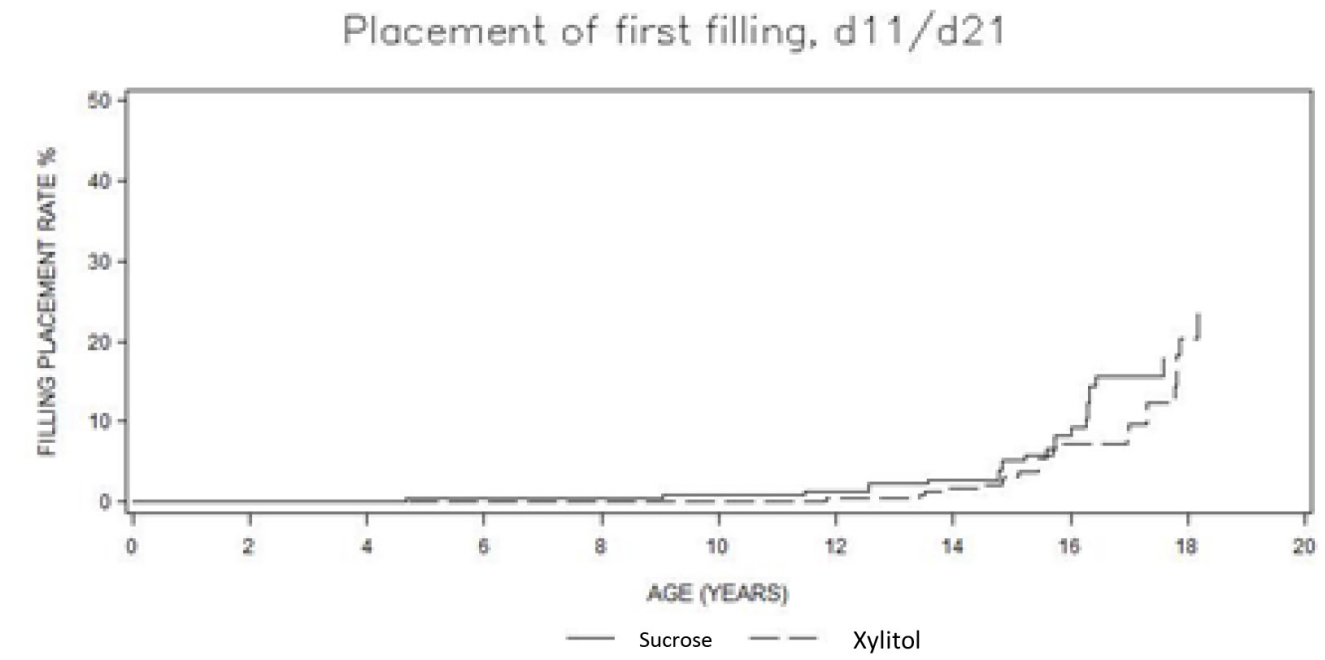

Placement of first filling, d11/d21

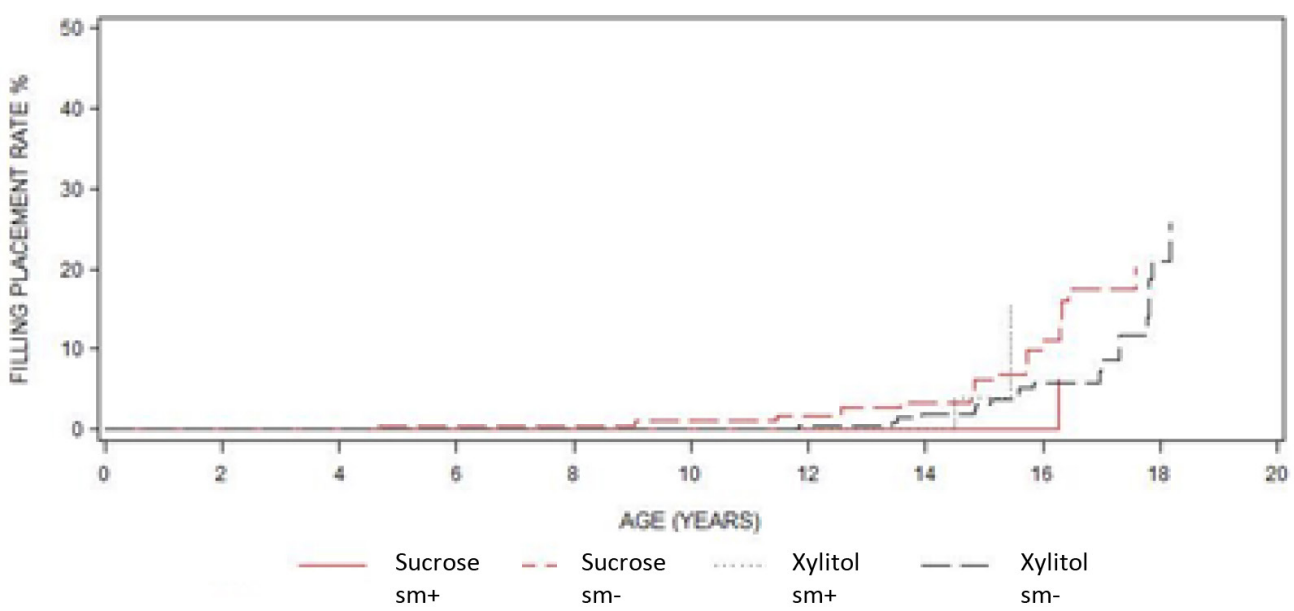

Figure 2. Kaplan-Meier survival functions of permanent maxillary incisors. In the upper figure according to sucrose/xylitol group and in the lower figure according to sucrose/xylitol group and mutans streptococci levels (ms+/ms-). Table 4. Distribution of individuals in sucrose (A) and xylitol (B) groups according to salivary mutans streptococci (ms) levels at baseline and after two months' sucrose/xylitol intervention. A group missing values for 10 individuals and B group missing values for 19 individuals.

Table 4. Distribution of individuals in sucrose (A) and xylitol (B) groups according to salivary mutans streptococci ( $\mathrm{ms}$ ) levels at baseline and after two months' sucrose/xylitol intervention. A group missing values for 10 individuals and B group missing values for 19 individuals.

A

\begin{tabular}{|c|c|c|c|c|c|c|}
\hline \multicolumn{7}{|c|}{ After the trial } \\
\hline $\begin{array}{c}\text { Sucrose } \\
\text { group }\end{array}$ & ms 0 & ms 1 & ms 2 & ms 3 & $\begin{array}{c}\text { Total n } \\
(\%)\end{array}$ \\
\hline At baseline & ms 0 & $82.7 \%$ & $7.7 \%$ & $7.7 \%$ & $1.9 \%$ & $52(42.6)$ \\
\hline & ms 1 & $63.9 \%$ & $19.4 \%$ & $0 \%$ & $16.7 \%$ & $36(29.5)$ \\
\hline & ms 2 & $38.9 \%$ & $33.3 \%$ & $11.1 \%$ & $16.7 \%$ & $18(14.8)$ \\
\hline & ms 3 & $25.0 \%$ & $12.5 \%$ & $6.3 \%$ & $56.3 \%$ & $16(13.1)$ \\
\hline Total n (\%) & & $77(63.1)$ & $19(15.6)$ & $7(5.7)$ & $19(15.6)$ & $122(100.0)$ \\
\hline
\end{tabular}

B

\begin{tabular}{|c|c|c|c|c|c|c|}
\hline \multicolumn{7}{|c|}{ After the trial } \\
\hline $\begin{array}{c}\text { Xylitol } \\
\text { group }\end{array}$ & ms 0 & ms 1 & ms 2 & ms 3 & $\begin{array}{c}\text { Total n } \\
(\%)\end{array}$ \\
\hline At baseline & ms 0 & $85.7 \%$ & $8.9 \%$ & $3.6 \%$ & $1.8 \%$ & $56(45.5)$ \\
\hline & ms 1 & $80.0 \%$ & $14.3 \%$ & $5.7 \%$ & $0 \%$ & $35(28.5)$ \\
\hline & ms 2 & $87.5 \%$ & $0 \%$ & $12.5 \%$ & $0 \%$ & $16(13.0)$ \\
\hline & ms 3 & $37.5 \%$ & $6.3 \%$ & $0 \%$ & $56.3 \%$ & $16(13.0)$ \\
\hline Total n (\%) & & $96(78.1)$ & $11(8.9)$ & $6(4.9)$ & $10(8.1)$ & $123(100.0)$ \\
\hline
\end{tabular}


Päkkilä J, Hangasmaa H, Halunen I, Laitala M-L and Anttonen V (2019) Long-Term Effect of a Short Sucrose/Xylitol Exposure on Survival of Permanent Teeth: A Practice-Based Study

Placement of first filling, d16/d26

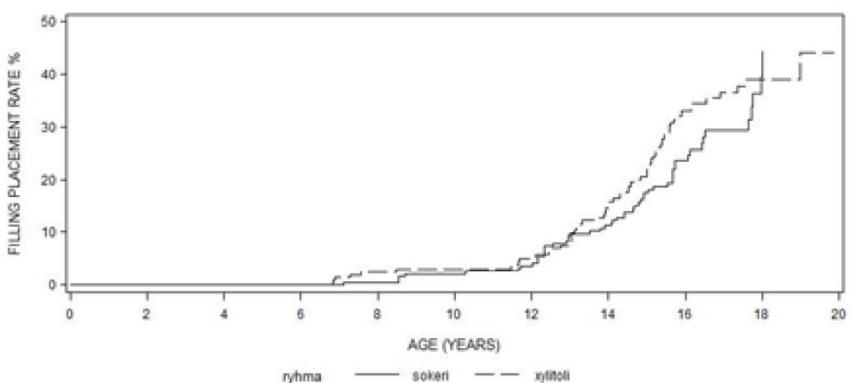

nyhma - soker -- xmos

Placement of first filling, $d 36 / d 46$

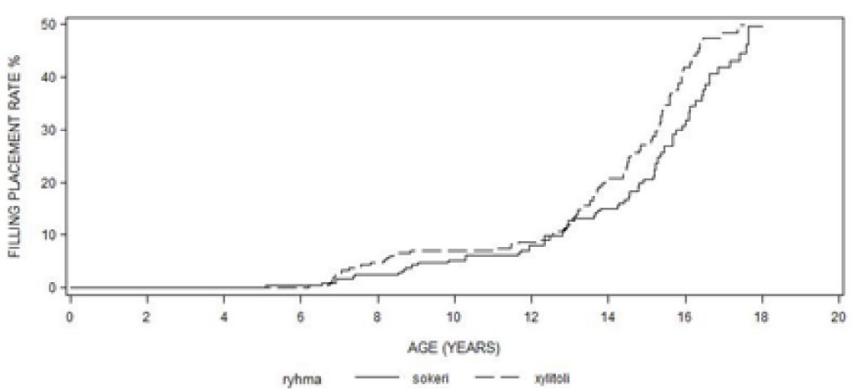

Placement of first filling, $d 17 / d 27$

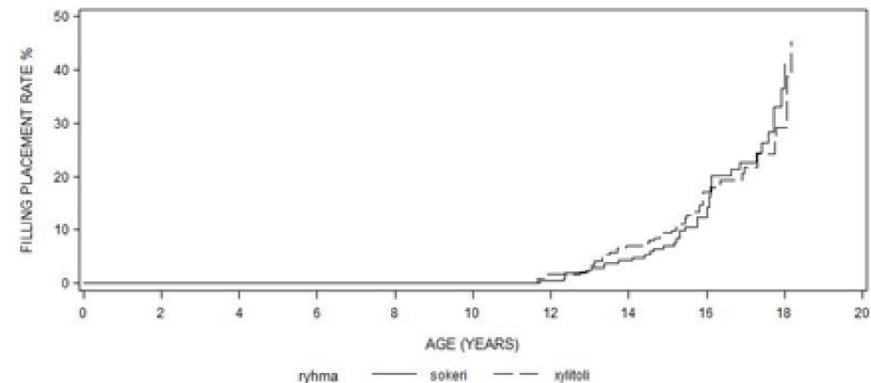

Placement of first filling, $d 37 / d 47$

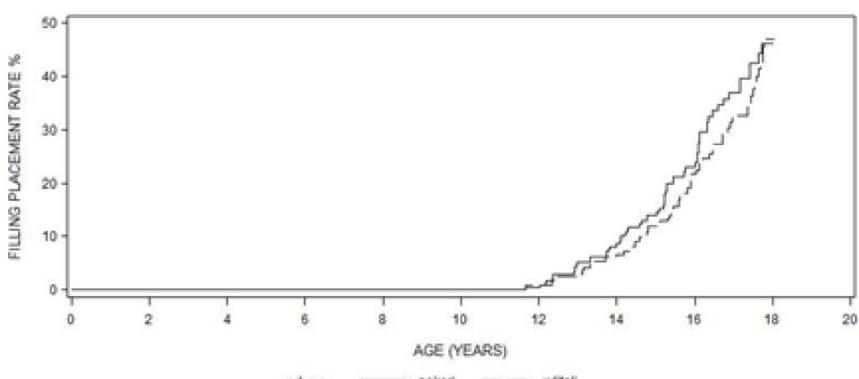

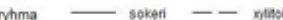

Figure 3. Kaplan-Meier survival functions of maxillary (upper) and mandibular (lower) first and second permanent molars according to xylitol and sucrose groups.

Placement of first filling, $\mathrm{d} 16 / \mathrm{d} 26$

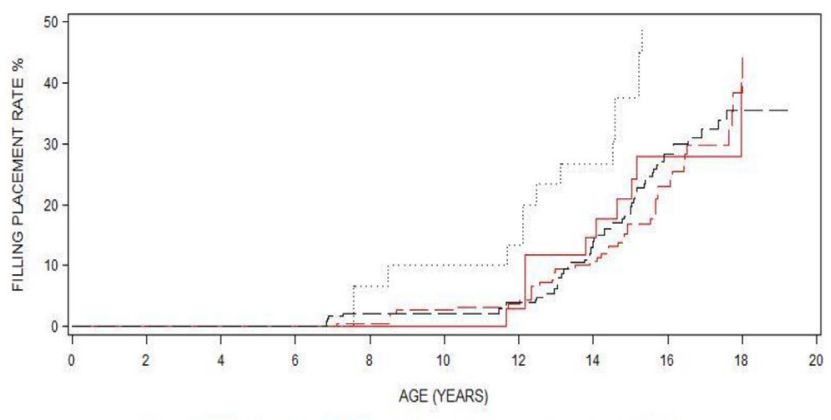

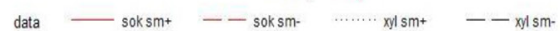

Placement of first filling, $d 36 / d 46$

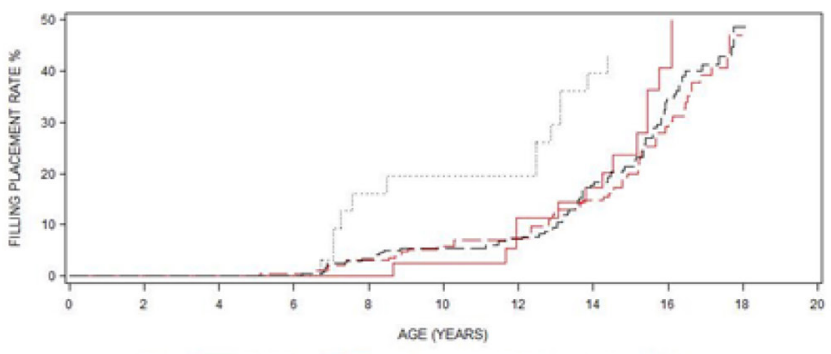

data -
Placement of first filling, $d 17 / d 27$

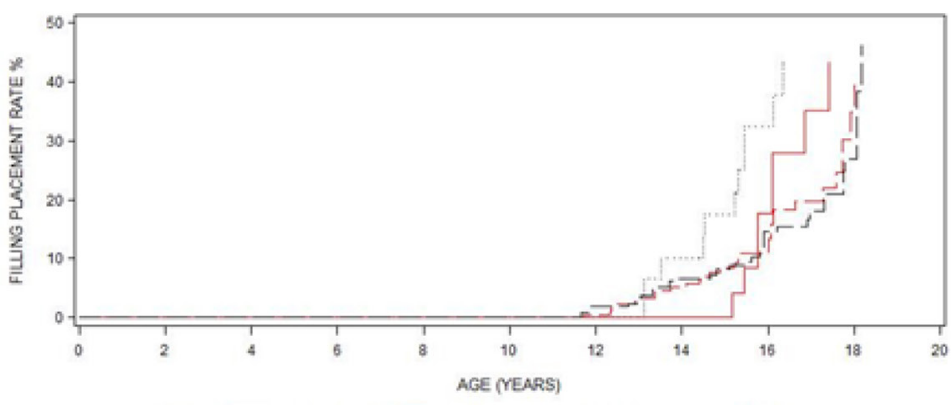

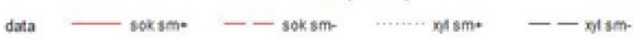

Placement of first filling, $d 37 / d 47$

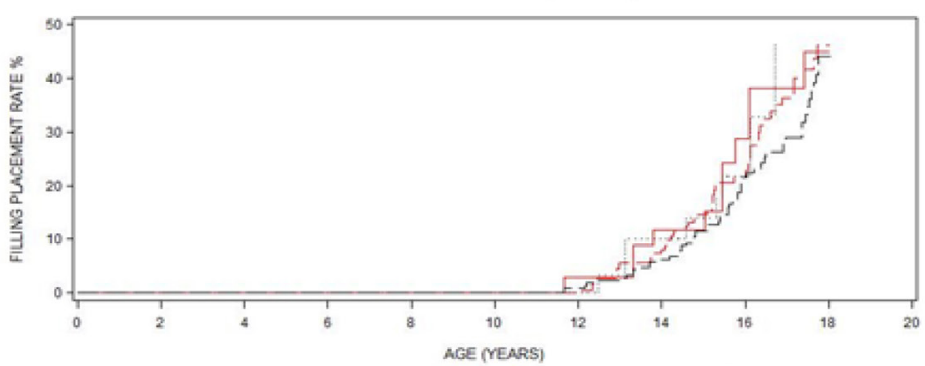

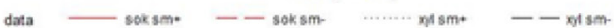

Figure 4. Kaplan-Meier survival functions of first and second permanent molars in maxilla (upper) and mandible (lower) according to sucrose/xylitol groups and salivary mutans streptococci levels (ms+/ms-). 
Median age for the placement of the first restoration in the first permanent molars was lower for individuals with ms+ in the xylitol group than in other subgroups; the difference between the groups was statistically significant for the first left lower molar, d. 36 ( $p=0.017$ ), but not for any other teeth (Figures 3 and 4). To describe the influence of caries status in childhood to that in the teenage a regression equation $\mathrm{DMFT}=2.55+0.65 *(\mathrm{dmf}+\mathrm{DMF})$ was achieved with $95 \%$ CI regression coefficient for $(\mathrm{dmf}+\mathrm{DMFT})$ being $(0.42,0.88)$.

\section{DISCUSSION}

Findings of the present study are in concordance with our hypothesis that a short sucrose/xylitol exposure at preschool age does not indicate decaying of permanent dentition during a 10 year-followup period regardless of the ms level at baseline. However, high ms level in preschool age does have some impact, it is somewhat associated with future decay in the first molars. The exposure was - luckily - too short for long-term effects of sucrose on permanent teeth even if there was a tendency that the first molars became decayed sooner in the sucrose than xylitol group. Same exposure for primary teeth was long enough to induce dental caries for children in the sucrose group when mutans streptococci levels were high [11].

Sucrose has been shown to be associated with dental caries prevalence since Vipeholm studies in 1954[12]. Regularly used polyolbased chewing gum, on the other hand, has been shown to prevent decaying among children and adolescents. In a 40-month doubleblinded cohort study in Belize, South America, xylitol chewing gum was the most effective factor in reducing caries incidence compared with no-gum, sucrose gum, xylitol-sorbitol gum and sorbitol gum. In the Belize study sucrose gum use somewhat increased caries incidence. In the same study it was discussed, if simultaneous increased salivary secretion due to activation of masticatory system caused the positive outcome by xylitol [13]. In the previous short-term study [11], two months' sucrose exposure was sufficient to cause decaying among those with high ms levels, but positive effect of xylitol in preventing caries was not seen. However, during the exposure there was a tendency that mutans streptococci levels of the participants changed towards better more often in the xylitol than in the sucrose group. In a recent study 5 weeks' exposure to xylitol reduced ms counts, but had no affect on oral microbiome [14]. After 6 months regular xylitol use (11.6 g a day) salivary ms consertration has been shown to be lower in a xylitol group than in a control (non-sucrose) group among school-children [15]. If the sucrose exposure had continued longer in the present study, the effect could have been detectable even in permanent teeth due to changes in the microbiota towards acidogenic and aciduric. Most likely the participants did not keep up sufficient xylitol consumption after the intervention. Indeed, during the followup time $17 \%$ of Finnish boys in secondary school reported never using xylitol chewing gum [16].

Participants were randomly divided into the sucrose and xylitol groups. Children with poor oral hygiene and high ms consentration could fall into either group. Unfortunately, there is no information about oral health-related habits and preventive dental care during the follow-up period. However, the original AOM research was justified by the fact that at that time all children were quaranteed regular check-ups [10].

During the 13 year follow-up period after the intervention, children with high ms levels at baseline had lower dental attendance rates than their ms negative counterparts. Irregular dental care of any risk patient may increase caries risk. One or more missed dental appointments has been shown to cause a significant risk dental caries [17]. It can be speculated that a peak in caries prevalence and consequently dental treatments among those in the sucrose group with high ms levels during the intervention may have caused dental fear and avoidance of dental visits. This was seen as higher prevalence of caries lesions in the first molars.

Most likely the participants continued normal lifestyle after the exposure and for example use of sugar among sucrose group participants returned to the normal level. Long-term harmful effects of a short-term exposure to any one risk factor like sucrose cannot cause the disease. Also long-term effects of sugar exposure can be modulated by regular daily fluoride [18]. This may be true for those, who are hospitalized for some time and good oral hygiene cannot be practiced. Never the less, everything must be done to keep good standard oral health care even during hospitalization.

Kaplan Meier curves and Wilcoxon test were used to describe and analyze the survival time of permanent teeth. This method offers a demonstrative instrument to monitore teeth surviving caries free and restorations not needing replacement in cohorts as a function of time [19-21]. There were no differences between maxillary or mandibular and first or second permanent molars when considering only xylitol and sucrose groups. Our findings concerning the association of $\mathrm{ms}$ colonization and dental decay are in line with previous long-term study [22]. When considering also ms level, the difference between molars are seen here even 13 years after the intervention. First molars in the xylitol ms+ groups deacyed sooner than second molars. The lower first permanent molars are the first ones to erupt, which may have influenced the outcome here. It seems that the only thing affecting the difference between the teeth is the ms level.

Linear regression model showed a statistically significant, linear association with the caries status in pre-school and in teenage. Thus, this retrospective study supports earlierfindings of caries history prediciting future caries experience [23].

Even though the research group was not monitored by the research team after primary sucrose/xylitol trial, Finnish health care system allows achieving valid data from patient records. As all children until 18 years of age are entitled to free dental care, practically all those at that age group are treated in public, municipaly organized oral health care. This is a huge benefit for a practice-based follow-up study like this.

It can be concluded that the short sucrose exposure in childhood did not increase the risk for dental decay in permanent teeth. In the long run the only factor that seemed to effect survival of permanent teeth caries free were low mutans streptococci levels. However, the effect was significant only for one lower first molar. 
Päkkilä J, Hangasmaa H, Halunen I, Laitala M-L and Anttonen V (2019) Long-Term Effect of a Short Sucrose/Xylitol Exposure on Survival of Permanent Teeth: A Practice-Based Study

CONFLICT OF INTEREST: The authors declare no conflict of interes

AUTHOR CONTRIBUTIONS: VA and IH conceived the ideas and designed the study; IH collected the data; JP, VA and HH analysed the data; $\mathrm{HH}$ and IH drafted the manuscript; VA and M-LL finalized the writing of the manuscript.

\section{REFERENCES}

1. Li Y. (2011) Controlling sugar consumption still has a role to play in the prevention of dental caries. J Evid Based Dent Pract. 11: 24-26. [Crossref]

2. Moynihan PJ, Kelly SA. (2014) Effect on caries of restricting sugars intake: systematic review to inform WHO guidelines. J Dent Res. 93: 8-18. [Crossref]

3. Tanzer JM. (1995) Xylitol chewing gum and dental caries. Int Dent J. 45(1 Suppl 1): 65-76. [Crossref]

4. Trahan L. (1995) Xylitol: a review of its action on mutans streptococci and dental plaque--its clinical significance. Int Dent J. 45(1 Suppl 1): 77-92. [Crossref]

5. Isokangas P, Tiekso J, Alanen P et al. (1989) Long-term effect of xylitol chewing gum on dental caries. Community Dent Oral Epidemiol. 17: 200-203. [Crossref]

6. Azarpazhooh A, Lawrence HP, Shah PS. (2016) Xylitol for preventing acute otitis media in children up to 12 years of age. Cochrane Database Syst Rev. 8: CD007095. doi: 10.1002/14651858.CD007095.pub3. [Crossref]

7. Uhari M, Kontiokari T, Niemelä M. (1998) A novel use of xylitol sugar in preventing acute otitis media. Pediatrics. $102: 879-84$. [Crossref]

8. Uhari M, Kontiokari T, Koskela M et al. (1996) Xylitol chewing gum in prevention of acute otitis media: double blind randomised trial. BMJ. 313: 1180-1184. [Crossref]

9. White G. (1996) Commentary: what about the ethics? Comment on: BMJ 313: 1180-1184. [Crossref]

10. Anttonen V, Larmas M, Raitio M. (1999) Children were guaranteed regular check ups in dental study. BMJ. 319: 432.

11. Anttonen V, Halunen I, Päkkilä J et al. (2012) A practise-based study on the effect of a short sucrose/xylitol exposure on survival of primary teeth caries free. International Journal of Paediatric Dentistry. 22: 356-362. [Crossref]

12. Gustafsson BE, Quensel CE, Lanke LS et al. (1954) The Vipeholm dental caries study; the effect of different levels of carbohydrate intake on caries activity in 436 individuals observed for five years. Acta Odontol Scand. 11: 232-264. [Crossref]

13. Mäkinen KK, Bennett CA, Hujoel PP et al. (1995) Xylitol chewing gums and caries rates: a 40-month cohort study. J Dent Res. 74: 1904-1913. [Crossref]

14. Söderling E, El Salhy M, Honkala E, Fontana M, Flannagan S, Eckert G, Kokaras A, Paster B, Tolvanen M, Honkala S. Effects of short-term xylitol gum chewing on the oral microbiome. Clin Oral Investig. 2015; 19: 237-44.

15. Campus G, Cagetti MG, Sacco G et al. (2009) Six months of daily high-dose xylitol in high risk schoolchildren: a randomized clinical trial on plaque $\mathrm{pH}$ and salivary mutans streptococci. Caries Res. 43: 455-461. [Crossref]

16. Lukkari E, Myöhänen J, Anttonen V et al. (2008) Dietary and oral hygiene habits: Room for improvement among schoolchildren. Finn Dent J 15:22-27. (Finnish, English abstract)

17. Wigen TI, Skaret E, Wang NJ. (2009) Dental avoidance behaviour in parent and child as risk indicators for caries in 5-year-old children. Int J Paediatr Dent.19: 431-437. [Crossref]

18. Bernabe E, Vehkalahti M, Sheiham A, Lundquist A, suominen AL. (2016) The shape of the dose response relationship between sugars and caries in adults. $J$ Dent Res. 95(2): 167-72.

19. Laitala ML, Alanen P, Isokangas P et al. (2013) Long-term effects of maternal prevention on children's dental decay and need for restorative treatment. Community Dent Oral Epidemiol. 41: 534-540. [Crossref]

20. Käkilehto T, Siiskonen J, Vähänikkilä H et al. (2013) Caries experience in primary teeth of four birth cohorts - a practice-based study. Eur Arch Paediatr Dent. 14: 59-64. [Crossref]

21. Vähänikkilä H, Käkilehto T, Pihlaja J et al. (2014) A data-based study on survival of permanent molar restorations in adolescents. Acta Odontol Scand. 72: 380-385. [Crossref]

22. Laitala M, Alanen P, Isokangas P et al. (2012) A cohort study on the association of early mutans streptococci colonisation and dental decay. Caries Res. 46: 228-233. [Crossref]

23. Kassawara AB, Tagliaferro EP, Cortelazzi KL et al. (2010) Epidemiological assessment of predictors of caries increment in 7-10-year-olds: a 2-year cohort study. J Appl Oral Sci. 18(2): 116-20 [Crossref]

Citation:

Anttonen V (2019) Long-Term Effect of a Short Sucrose/Xylitol Exposure on Survival of Permanent Teeth: A Practice-Based Study. J Clin Res Med Volume 2(2): 1-7. 